\title{
Reflexões sobre a música e suas funções: a Décade Philosophique e as artes na nova sociedade francesa
}

PAULO M. KÜHL

UNICAMP (pmkuhl@gmail.com)

\begin{abstract}
Xas discussões sobre as relações entre as artes e os movimentos políticos, o caso dos ideólogos na França do final do século XVIII apresenta elementos que ajudam a destrinchar as conexões entre o pensamento sobre a música em particular e uma militância filosófica, que se propõe a refletir sobre certos fundamentos da arte musical, bem como propor diretrizes para seu papel na nova sociedade. Tratar da Ideologia e de seus autores, em geral, traz algumas dificuldades, já que ela parece, como afirmava Georges Gusdorf (1978), ter sido jogada "nas lixeiras da história".

São diversas as razões desse esquecimento: a sombra da geração anterior (principalmente Voltaire e Rousseau), a mistura de homens de pensamento com homens de ação "filosofia militante da enciclopédia", como diz Joanna Kitchin (1965) - a proximidade com o primeiro-cônsul, que, ao tornarse Napoleão I, passa a perseguir os ideólogos, as críticas posteriores, sobretudo as mais recentes, à institucionalização da vida social e cultural na França, tudo contribuiu para o relativo esquecimento de um grupo de pensadores e de suas variadas publicações.
\end{abstract}

Dentre elas, uma de grande circulação e presença marcante na vida francesa entre 1794 e 1807, a Décade Philosophique, que congregava seus sócios (Pierre-Louis Ginguené, J.-B. Say, G.-J. S. Andrieux, G. Toscan, Amaury Duval, Joachim Le Breton) e diversos colaboradores. Calcula-se que eles eram aproximadamente 300, dos quais cerca de uma centena foram identificados. A presença marcante, com o fim do Terror, das mesmas pessoas em diversas esferas políticas francesas, no Instituto de França, no Muséum e na própria Décade indica a militância desses filósofos na construção da nascente república, com todas as dificuldades e contradições aí implicadas. 
O papel das artes nesses grandes projetos é essencial, ainda que a literatura sobre o assunto as tenha sempre deixado de lado ou em segundo plano. Se olharmos para as poucas mas importantes publicações sobre a Idéologie e a Décade, vemos o papel minúsculo que as artes nelas têm: Joanna Kitchin (1965) dedica ao assunto uma parte de um capítulo, Georges Gusdorf (1978) não se ocupa do tema, a coletânea organizada por Josiane Boulad-Ayoub (2003) traz dois dos nove volumes versando apenas sobre os espetáculos. Não se trata de uma queixa, mas de uma constatação reveladora: dentro das grandes transformações políticas e sociais que vão da Revolução até a Restauração, o assunto "artes" custa a encontrar, para os historiadores de hoje, um papel mais claro. É como se o tema fosse apenas de interesse do mundo da história da arte, ou da música, ou do espetáculo, mostrando que, mais uma vez, existe uma tensão e uma divisão muito grandes nas maneiras de olhar-se para as relações entre arte e sociedade.

Certamente não era essa a visão dos autores da Décade, nem a dos ideólogos em geral, uma vez que uma concepção com muitos ecos iluministas e sobretudo enciclopedistas guiava seus interesses. Difícil é, contudo, falar das artes como um todo, uma vez que havia certa divisão de tarefas dentro do grupo dos ideólogos e em seu veículo principal, a Décade. De qualquer modo, alguns princípios gerais podem ser identificados: o primeiro deles é certamente a crença em um progresso constante. Não se trata de uma novidade, se olharmos para o passado mais recente do século XVIII (em autores como Chénier, Condorcet, Mme de Staël), mas adota-se uma visão da história como uma constante possibilidade de aperfeiçoamento (KITCHIN, 1965, p. 139-145). Uma das preocupações dominantes do grupo é expor os progressos de ordem intelectual (nas ciências morais e políticas), o que poderia ser estendido a todos os domínios da atividade humana.

Note-se que não se trata de um movimento homogêneo, já que, apesar de a Revolução ter estabelecido definitivamente a ideia de progresso, ela também trouxe o culto da tradição e das coisas antigas, o que pode ser verificado nos ataques promovidos por publicações como o Mercure de France 
e o Gênio do Cristianismo de Chateaubriand, revelando desconfianças, com motivos religiosos, em relação aos mesmos elementos louvados pela Décade. De qualquer modo, para os adeptos dessa visão progressista da história, o progresso moral também seria certo, apesar das diversas contradições apontadas por fatos mais recentes, como o Terror ou as várias ingerências do estado no funcionamento das instituições e da imprensa. Assim, as numerosas questões propostas pelo Institut de France (assim como, em certa medida, já ocorria nas Academias), visavam resolver questões que afligiam a organização da sociedade e, dentre elas, surgia o papel das artes.

Há seguramente uma visão "republicana" das artes, que já havia despontado, por exemplo, nas diversas pinturas de David que antecederam a Revolução. Se olharmos para o primeiro prospecto da Décade, de 1794, vemos os diversos interesses que se anunciam. Reconhecendo as transformações recentes, o jornal enfatiza o papel da filosofia e dos filósofos nessa nova sociedade:

Em meio ao movimento geral e às crises revolucionárias, a razão e a filosofia meditam em silêncio, conduzindo os eventos às causas e aos princípios, e fazendo descer os fatos às consequências; elas buscam os meios de tornar úteis à Pátria suas aproximações e sua previdência. (apud BOULADAYOUB, 2003, t. I, p. 50)

Em seguida surgem os temas: as ciências, a economia política, as artes mecânicas, as letras e finalmente as belasartes, quando o discurso se torna mais enfático:

[...] chamadas à sua dignidade primeira, elas não mais se limitam em suas invenções a lisonjear os gostos desprezíveis dos poderosos e dos ricos ociosos, nem a distrair um povo escravo e miserável dos sentimentos de seus males. Elas se sentem destinadas a elevar os espíritos, aquecer as almas, engrandecer a imaginação com ideias elevadas, sentimentos enérgicos e nobres imagens. Comprimidas pelo despotismo, é somente em uma república que seu gênio republicano poderia ter todo o seu desenvolvimento. (apud BOULADAYOUB, 2003, t. I, p. 50). 
Aqui é possível destacar pelo menos dois elementos. 0 primeiro deles, diz respeito a essa nova pátria da cultura e das artes que seria a França. Em uma argumentação um tanto perversa, um grupo de pensadores, com o intuito de justificar o transporte para Paris das obras pilhadas pelas tropas napoleônicas, afirmava que esse seria o melhor destino para elas, justamente por ali poderem encontrar uma pátria de liberdade, a mais apropriada para seu desenvolvimento ${ }^{1}$. Assim, após a Revolução, a França poderia equiparar-se à Grécia antiga em seu esplendor e como pátria, agora definitiva, das artes.

O segundo relaciona-se a uma visão sobre as artes, às vezes perigosamente normativa. De um lado, o jornal reconhecia na pintura, na escultura e na arquitetura seu caráter imitativo, e daí tornava-se "fácil traçar a linha que lhes é conveniente prescrever"; de outro, enxergava na música e na dança teatral, "artes mais móveis e cuja expressão mais vaga lhes dá teorias móveis e vagas como elas" (apud BOULADAYOUB, 2003, t. I, p. 54). Assim, ao finalmente chegar à música, os redatores do jornal perceberam uma dificuldade maior, já que a música, considerada isoladamente, seria menos suscetível de prescrição. Está aqui em disputa o caráter imitativo ou representativo da arte musical. Os autores recordam que a música, "acusada até aqui de frivolidade, foi vista pelos antigos como a mais grave e a mais importante das artes" (apud BOULAD-AYOUB, 2003, t. I, p. 54) e que ela poderia recuperar "em parte" esse grande caráter - e novas reflexões possibilitariam reconduzir a música à sua dignidade original.

Não se trata exatamente de uma novidade, pois desde o século XVI, pelo menos, houve várias propostas de recuperação de uma antiguidade que também parece se transformar no tempo. E é necessário lembrar que o século XVIII é atravessado por tentativas de reformas as mais variadas e de polêmicas e

\footnotetext{
1 Para uma discussão sobre o assunto, veja-se a introdução de E. Pommier a QUATREMÈRE DE QUINCY (1989), POMMIER (2000) e LENIAUD (2007).
} 
querelas, no mais das vezes, procurando recuperar-se uma ou outra característica da música antiga. Mas desta vez, trata-se de um engajamento político das artes, em certa medida equiparável, ainda que por vias tortas, às reformas moralistas do século XVIII, tais como aquelas propostas por Luigi Riccoboni e pelos moralistas católicos.

Há, contudo, especificidades nas propostas para cada uma das belas-artes. No caso da pintura histórica e da retratística, por exemplo, Pierre Bordes mostrou a dificuldade em se representar o "real" recente com os meios herdados das poéticas clássicas. 0 autor insiste que, para a arte revolucionária, nem as normas do academicismo do Ancien Régime, nem o romantismo da Restauração davam conta do que estava acontecendo e da pluralidade de propostas surgidas (BORDES, 2010, p. 17). A representação de fatos recentes poderia assemelhar-se a cenas de gênero, retratos coletivos, ou alegorias históricas. A tarefa para os artistas que se propusessem a representar fatos recentes era grande: escapar da pintura de gênero e encontrar novos tipos de representação. Segundo o autor, é primeiramente na gravura e na caricatura que surgiu uma maneira mais adequada de representar o novo heroísmo. Em seguida, modelos ingleses e americanos servem como exemplos de possíveis guinadas, para finalmente haver grandes transformações. E junto vêm outras questões: a representação em pintura confere uma maior dignidade, mesmo aos atores anônimos; os anônimos, na verdade, tornamse atores, o que era uma novidade; há fatos que são obra de todos (como as jornadas revolucionárias) e "fatos particulares" e as ações virtuosas dos cidadãos da história recente não são mais fixadas para sempre, mas abre-se à interpretação e à avaliação.

Mas no caso da música, o problema assume outras dificuldades. Em primeiro lugar, é necessário lembrar que, no mundo francês do século XVIII, quando se pensa em música, é sobretudo a música vocal que está em jogo. Por exemplo, o título do livro do Conde de Lacépède (1785) soa, para nós, um tanto enganoso: La poétique de la musique. É importante ressaltar, como pode ser visto através do índice da obra, que aquilo que o autor chama de poética da música, é, na verdade, 
uma poética da ópera. Ainda que trate da música de igreja, da música vocal, da de concerto, da de câmera, e da música instrumental, o foco e o princípio de toda discussão estão na música teatral, ou seja, na ópera. É igualmente dentro do terreno da música vocal que as poucas reflexões sobre a música apareceram na Décade Philosophique. o primeiro interesse, ou, pelo menos, o primeiro assunto em que a música aparece mais claramente está nos relatos das festas republicanas, vistas como essenciais para a construção de um novo tipo de cidadania. A música, na visão do jornal, apela para o sentimento e para o coração, mais do que à razão, o que torna as festas mais eficazes. 0 principal crítico das artes na Décade era Amaury Duval, sob o pseudônimo de Polyscope - o ideal era, como se viu, retomar a dignidade da arte dos antigos, já que, segundo a concepção revolucionária, a liberdade política e as belas-artes nasceriam sempre sob o mesmo sol. Pensamento, aliás, que estará na justificativa para trazer as obras de arte da 186 Europa para Paris.

A crítica de Duval é sobretudo contra o luxo de determinados concertos ("podemos pagar, por apenas uma ariazinha, uma quantia que seria suficiente para a subsistência anual de toda uma família? E nós somos republicanos! Sim, como os romanos sob Augusto)"2. Mas o autor aproxima-se um pouco mais da música, sempre com suas preocupações republicanas:

O que é hoje a música? Uma junção de sons vãos, inexpressivos, frequentemente bizarros e rebuscados. Digam-me o que o autor quis pintar em uma sinfonia, que começa com timbales, com um barulho horrível, ao qual sucedem frases ternas, langorosas, interrompidas novamente por escândalos, ou por acordes insignificantes. Não, a música não é mais uma arte de imitação. Um republicano pode passar quatro horas em um espetáculo que não lhe ensina nada ao espírito, que não comove nenhuma alma [...] Para que tais espetáculos possam ser úteis em uma república, seria necessário que homens instruídos na arte da

2 La Décade Philosophique, 30 Frimaire An III (20/12/1794) (apud KITCHIN, 1965, p. 227). 
declamação viessem cantar bons versos; contar, sobre árias simples, fáceis, mas expressivas, alguns fatos interessantes, sejam de guerra, sejam de amor (apud KITCHIN, 1965, p. 228).

Aqui vemos a repetição de uma antiga queixa (Sonate, que me veux-tu? enunciada pela primeira vez por Bernard de Fontenelle), repetida por Rousseau, contra a música puramente instrumental. Além disso, a necessidade, na visão do autor, de encontrar-se uma música apropriada às novas palavras de ordem torna-se imperiosa, e pôde ser ouvida, por exemplo, no Hino ao ser supremo (DESORGUES; GOSSEC, 1794) ou na própria Marselhesa. Cabem aqui algumas considerações sobre as duas composições. Como é sabido, o Chant de guerre pour l'Armée du Rhin, cuja letra é de autoria de Rouget de Lisle, apareceu em 1792 em Estrasburgo e só posteriormente foi chamado de $A$ Marselhesa. Há um debate sobre a origem da composição musical, que tem várias fontes apontadas como possíveis $^{3}$. Ainda que a questão não tenha sido totalmente decidida, importa aqui, de um lado, reconhecer o uso de fontes musicais anteriores, com um texto que lhe foi atribuído posteriormente; de outro, cabe olhar para os cantos antirrevolucionários, que aproveitaram a melodia da Marselhesa e de algum modo opuseram-se ao hino belicoso e patriótico, com diversas versões de textos ${ }^{4}$. A intenção certamente era desconstruir o hino original, aproveitando-se do sucesso de sua música, e em certa medida explicitando a concepção de que a música podia, em princípio, significar qualquer coisa.

Paródias e contrafacta musicais constituíam um procedimento musical com fundamentos na poética e na retórica, já há muito utilizado na história das composições na Europa e, dentro das rápidas transformações do período revolucionário, funcionaram como um importante meio de persuasão e também de crítica. Mas, se a discussão sobre a

\footnotetext{
3 Para um rápido debate mais recente, veja-se LA FACE (2016).

4 Para uma versão de conjunto dos textos e algumas de suas implicações, veja-se HUDDE (1985).
} 
relação entre palavra e música é uma constante na história do pensamento sobre a arte musical, é visível nas últimas décadas do século XVIII uma preocupação crescente com o assunto. No segundo volume de seu extenso Le Rivoluzioni del teatro musicale italiano, Stefano Arteaga, em oposição às ideias de Vincenzo Manfredini, critica diversos procedimentos de composição das óperas, os quais desrespeitariam uma série de qualidades do poema em que se baseiam, pois a música feita para uma ária não poderia ser usada em outra poesia:

(...) quem quisesse ou mudar árias, ou acomodar o motivo, os acompanhamentos e a expressão total em uma outra poesia não faria outra coisa a não ser destruir de fato sua verdade musical. E é este precisamente o sinal mais decisivo de excelência [das árias] (ARTEAGA, 1785, II, p. 308-309)

A constatação é que os compositores desprezavam tais qualidades e por isso mudavam suas composições, adaptando suas músicas a qualquer texto. Para reforçar sua argumentação, Arteaga comenta uma ária (Già presso al termine) do personagem Farnaspe, na ópera Adriano in Siria de Metastasio, escrita por Gennaro Astaritta (ARTEAGA, 1785, p. 310-314). 0 autor apresenta um novo poema para a ária, construindo um contexto diametralmente oposto ao original; a música teria o mesmo efeito e ele também dá um exemplo com outro texto, desta vez em francês, para provar que "não se encontra na música teatral moderna aquele escopo, aquele fim último, aquela unidade de expressão e de tema, ao qual todas as coisas deveriam referir-se na música, assim como tudo se refere à unidade de ação na tragédia" (ARTEAGA, 1785, t. II, p. 313314). Ou seja, a música contemporânea dele seria genérica e serviria a qualquer propósito.

Tal questão também aparecerá mais tarde, sendo então abordada por Hanslick, em seu Do belo musical, no capítulo intitulado "'A representação do sentimento' não é o conteúdo da música". Aqui o autor afirma que "numa composição vocal, não são os sons que representam o conteúdo, mas o texto" (HANSLICK, 1992, p. 44). Para justificar tal asserção, é discutido o exemplo da grande ária do Orfeu e Eurídice de Gluck U'ai perdu mon Euridyce/Rien égale mon malheur), afirmando, junto com Boyé, que seria possível substituir o texto por J'ai 
trouvé mon Euridyce/Rien égale mon bonheur, indicando assim uma eventual imperícia do compositor em representar a tristeza. É Massimo Mila (1965 [1947]) quem responde a essa crítica, em primeiro lugar com uma epígrafe retirada de um comentário de Mendelssohn ${ }^{5}$; depois mostrando que Hanslick tomou a versão francesa da ópera, com libreto de Pierre-Louis Moline, e não se deu conta de que o original italiano mostrava uma sequência de indagações e dúvidas (Che farò senza Euridice?/Dove andrò senza il mio ben?) e não, a plena tristeza (ou alegria) do personagem. Também afirma que:

(...) certamente a música exprime movimentos e aspectos da alma humana, mas precisamente porque estes aspectos espirituais encontram sua expressão em música, e não em prosa ou em poesia, eles não podem ser designados perfeitamente com palavras, e apenas por uma aproximação descritiva nós podemos falar de dor, alegria, desespero, esperança, etc.: todas objetivações abstratas de sentimentos que, por terem encontrado sua expressão verbal, não correspondem exatamente àqueles movimentos da alma específicos que encontram sua forma em uma determinada música. E sabe-se que nessas coisas é impossível distinguir forma de conteúdo. (MILA, 1965 [1947, p. 21-22]).

Assim, Mila tenta provar que a música para aquela ária de Gluck, justamente o pai de uma grande "reforma" da ópera, não serviria a qualquer situação.

No caso de Gossec e seu Hino ao ser supremo, destacamos a proposta de criar uma música relativamente simples para as palavras propostas pelo poema de Desorgues. A descrição da festa do Ser Supremo, com sua longa cerimônia, é bem conhecida ${ }^{6}$, mas alguns cuidados são necessários. Em primeiro lugar, como indica Darlow (2012, p. 178), havia uma

5 "Para mim os pensamentos que a música exprime não são indefinidos demais, mas demasiado definidos para serem descritos com palavras".

6 Veja-se, entre tantos outros, Fêtes et Révolution. Catálogo de exposição. Paris: Dijon, 1989. 
série de negociações entre os órgãos de censura (Comité d'instruction publique, Commission d'instruction publique e a Commune), oscilando com relação ao teor das peças apresentadas: entre música de propaganda e aquela com certa qualidade artística, mesmo antes do Terror, havia a preocupação com os rumos da arte dita revolucionária. Em segundo, é importante lembrar que Gossec, assim como tantos outros compositores, era adepto da prática de parodiar suas próprias composições, usando aquelas originalmente religiosas ou teatrais para os novos hinos e cantos revolucionários (JAM, 1992, p. 230), e que as óperas também logo aderiram ao uso de árias e canções populares ${ }^{7}$. Desse modo, nota-se que, apesar do cuidado de determinados compositores em criar obras cuja relação entre o texto e a música fosse das mais íntimas, a prática de utilizar músicas já compostas com outros textos era corrente, criando novas camadas de significados. Em terceiro lugar, como indica Kaci (2010), os diversos tipos de 190 apropriação dos cantos revolucionários, em Paris e nas províncias, revelam uma pluralidade de significados que escapam da função informativa ou da mera propaganda política.

Os autores da Décade Philosophique tinham uma visão relativamente crítica sobre a literatura e a arte de "ocasião", especialmente em relação às pequenas peças e poemas que foram surgindo ao longo do período revolucionário ${ }^{8}$; mas ao mesmo tempo, pelo menos na visão de Duval, a música continuava sendo serva da poesia, desta vez, uma nova poesia engajada. Aqui vemos algumas das limitações de um tal projeto, com a tentativa de construir-se uma música "simples", de fácil

\footnotetext{
7 Para detalhes da produção de Gossec no período revolucionário, veja-se ROLE (2015, p. 129-182). Ver também Kaci (2010, p. 83), que lembra que "durante o decênio revolucionário, de acordo com o catálogo de Constant Pierre, 93,5 \% das obras foram escritas sobre [...] estruturas musicais conhecidas do grande público".

8 Vejam-se os volumes VIII e IX ("Spectacles"), de Martin Nadeau, em BOULAD-AYOUB (2003).
} 
apelo, sobre um texto inspirador - com isso, desconsideram-se por completo os sucessivos esforços próprios do fazer musical em locais variados. Mas a partir de 1796/97, é Ginguené que assume a principal tarefa de crítica musical na revista. Grande historiador da literatura italiana, homem de uma cultura mais mundana e mais universal, ele é responsável, sobretudo, pela rubrica "Instrução pública" no jornal. Além disso, é, junto com Framéry, o editor da parte musical da Enciclopédia, com comentários e acréscimos ${ }^{9}$.

Ainda que sensível às festas e aos hinos republicanos (especialmente a Marselhesa), ele era um grande admirador da música em geral, de Palestrina e Pergolese, das sinfonias de Haydn, dos cantores da moda, enfim de uma vida musical mais ampla (KITCHIN, 1965, p. 228). Nesse sentido, insistiu constantemente na necessidade de uma educação musical formal e no cultivo do gosto público, para além das peças de ocasião. Mesmo acreditando em alguns elementos da arte republicana, Ginguené reservou à música um status diferente, mais associado aos diletantes cultivados, sem conseguir subordinar (ou seja, censurar) a produção musical a ideais políticos. De certo modo, parece haver um alinhamento com as ideias de Auguste Étienne de La Chabeaussière, incumbido principalmente da crítica de espetáculos a partir de 1796, que pensava que nos períodos de revolução seria melhor evitar os temas políticos, justamente por sua volatilidade. As artes, na Décade, acabam assumindo várias funções: de instrução (Ginguené), uma diversão menor (já que haveria assuntos mais importantes como o cultivo da terra - J.-B. Say : "a instrução que encontramos no teatro não paga o tempo que lá se perde"10); e, por fim, uma visão mais ampla, às vezes distante da política, contra o nivelamento dos espíritos.

${ }^{9}$ Encyclopédie Méthodique publiée par MM. Framery et Ginguené. Paris: chez Panckoucke, 1791.

${ }^{10} \mathrm{~A}$ frase está na Décade, sob o pseudônimo de Boniface Véridick (Décade Philosophique, 30/03/1796 - 10 germinal an IV- , p. 38-44). 
Aqui se delineia também uma "dificuldade" com relação à música: percebida, de um lado, como "abstrata", ela só pode funcionar em um projeto político através do texto a ela associada - pelo menos neste momento na França, e também através de algum tipo de educação sistemática. Assim como outras manifestações artísticas atreladas a propostas políticas muito precisas de outros períodos, especialmente dos governos totalitários do século XX, a visão de que tal produção seria de mera propaganda em geral impediu estudos mais sutis, o que só vem acontecendo nas últimas décadas. De outro lado, talvez justamente por causa do caráter "destacado" da música, ela pode continuar sendo uma arte do prazer, ecoando sempre a máxima horaciana do útil e do agradável. Não é de se estranhar, pois, que a música tenha aparecido pouco dentro do projeto da Décade: as artes do desenho, mas, sobretudo, os espetáculos, serão os verdadeiros objetos de discussão, porque aparentemente teriam uma maior capacidade de mobilizar os

192 novos atores da história. Para caber no projeto político, seria necessário domesticar a música e subordiná-la ao texto, restando poucas opções para a criação musical. Isso talvez nos sirva de alerta para os problemas e as contradições constantes das relações entre música e política.

\section{Referências bibliográficas}

ARTEAGA, S. Le Rivoluzioni del teatro musicale italiano dalla sua origine fino al presente. 2a. ed. Veneza: Carlo Palese, 1785.

BORDES, Pierre. Représenter la Révolution. Les Dix-Août de Jacques Bertaux et de François Gérard. Lyon: Fage, 2010.

BOULAD-AYOUB, J. (Org.). La Décade Philosophique comme système 1794-1807. Rennes: Presses Universitaires de Rennes, 2003.

BRÉCY, Robert. "La chanson révolutionnaire de 1789 à 1799. In Annales historiques de la Révolutionn française, 53e année, n. 244, p. 279-303, 1981.

DARLOW, Mark. Staging the French Revolution: Cultural Politics and the Paris Opera, 1789-1794. Oxford: Oxford University Press, 2012. 
DESORGUES, Théodore; GOSSEC, Fraçois-Joseph. Hymne à l'être suprême. Paris: Magasin de musique à l'usage des fêtes nationales, 1794.

FÊTES ET RÉVOLUTION. Catálogo de exposição. Paris: Dijon, 1989.

GUSDORF, Georges. LA CONSCIENCE RÉVOLUTIONNAIRE: Les idéologues. Paris: Payot, 1978.

HANSLICK, Eduard. Do belo musical: uma contribuição para a revisão da estética musical. Trad.: Nicolino Simone Neto. Campinas: Editora da Unicamp, 1992.

HUDDE, Hinrich. "Contre-Marseillaises. Politische Gegentexte der Revolutionsjahre auf Rouget de Lisles Melodie". In Zeitschrift für französische Sprache und Literatur, Bd. 95, H. 3, p. 279-308, 1985.

JAM, Jean-Louis. Marie-Joseph Chénier and François-Joseph Gossec: two artists in the service of Revolutionary propaganda. In BOYD, Malcolm (Org.). Music and the French Revolution. Cambridge: Cambridge University Press, p. 221-235, 1992.

KACI, Maxime. Chanter la politique: partitions nationales et modulations septentrionales (1789-1799). In Annales historiques de la RÉVOLUTION FRANÇAISE, 362, P. 79-99, 2010.

KITCHIN, J. Un journal "philosophique": La Décade (1794-1807). Paris: Lettres modernes, 1965.

LACÉPÈDE, B. G. E. M. La Poétique de la Musique. Paris: L'Imprimerie de Monsieur, 1785

LA FACE, Giuseppina. La Marsigliese e il mistero attorno alla sua paternità. In Il Fatto Quotidiano, 10/01/2016. Disponível em: http://www.ilfattoquotidiano.it/2016/01/10/la-marsigliese-e-ilmistero-attorno-alla-sua-paternita/2361661/ . Acesso em 13.03.2016.

LENIAUD, J.-M. Joachim Le Breton et Antoine Quatremère de Quincy, secrétaires perpétuels de l'Académie des Beaux-Arts: deux conceptions divergentes du musée. In CARACCIOLO, M. T.; TOSCANO, G. (Org.). Jean-Baptiste Wicar et son temps, 1762-1834. Villeneuve d'Ascq: Presses Universitaires du Septentrion, p. 79-91, 2007.

MILA, Massimo. "Che farò senza Euridice". In L'esperienza musicale e l'estetica. Turim: Piccola Biblioteca Einaudi, p. 20-23, 1965 [1947].

MOUREAU, François. Stratégie chansonnière de la Révolution française. In The French Review, Vol. 62, No. 6, p. 967-974, 1989. 
POÉSIES révolutionnaires et contre-révolutionnaires ou recueil, classé par époques, des Hymnes, Chants guerriers, Chansons républicaines, Odes, Satires, Cantiques des Missionnaires, etc., etc., Les plus remarquables qui ont parues depuis trente ans. T. I. Paris: A la Librairie Historique, 1821.

POMMIER, E. Quatremère de Quincy et le patrimoine. In PAVANELLO, G. (Org.) Antonio Canova e il suo ambiente artistico fra Venezia, Roma e Parigi. Veneza: Istituto Veneto di Scienze, Lettere ed Arti,, p. 459-479, 2000.

QUATREMÈRE DE QUINCY, A. C. Lettres à Miranda sur le déplacement des monuments de l'art de l'Italie (1796). Introduction et notes par Édouard Pommier. Paris: Macula, 1989.

ROLE, Claude. François-Joseph Gossec: (1734-1829): Un musicien à Paris, de l'Ancien Régime à Charles X. Paris: L'Harmattan, 2015.

ROUGET DE LISLE, Claude Joseph. Chant de guerre pour l'Armée du Rhin. Paris: Bignon, 1792. Disponível em: http://gallica.bnf.fr/ark:/12148/btv1b9067388h/f2.image.r=la\%20m arseillaise. Acesso em 13.03.2016. 